\title{
THE COMPLICATIONS OF GASTRIC AND DUODENAL ULCER
}

\author{
By A. K. Monro, M.A., M.D., F.R.C.S. \\ Assistant Lecturer in Surgery, Post Graduate Medical School of London; Surgeon, Southend General Hospital, and \\ St. Fohn's Hospital, Leicester Square
}

\section{HAEMORRHAGE}

Haemorrhage is the commonest complication of gastric and duodenal ulceration. It has been estimated to occur, in gross form, in about 20 per cent of all cases. It may be of any degree, from the slight haemorrhage which only discolours the stools or the persistent small haemorrhages which cause a severe anaemia, to the more common, profuse and dramatic haematemesis which at times is so severe as in a few minutes to endanger the patient's life.

\section{Pathology}

In acute gastric erosions haemorrhage is a common complication but, being caused by a superficial lesion, it does not endanger life. In more penetrating acute gastric or duodenal ulcers haemorrhage may be severe and even, on occasion, fatal ; this is, however, a rare event.

In all active chronic peptic ulcers minute haemorrhages are almost constant as shown by the presence of occult blood in the stools. Such bleeding comes from small vessels in the walls of the ulcer. Larger vessels, however, may be involved, particularly the pancreaticoduodenal, left gastric and more rarely the splenic arteries and their branches. As the arterial wall becomes eroded, a time comes when the wall is unable to contain the pressure of the arterial pulse and haemorrhage occurs. In the case of a large vessel brisk haemorrhage continues probably for ro- 5 minutes in which time 2-3 pints of blood may be lost. From rapid distension of the stomach the patient is likely to vomit, whilst from loss of blood he feels weak or faints. Various factors then come into play which tend to stop the haemorrhage, namely :-

(a) Fall of blood pressure.

(b) Retraction of the inner coat of the vessel.

(c) The coagulability of the blood.

In favourable circumstances a clot forms in the open vessel. If this clot is allowed to become firm, danger is, at least temporarily, past. Any variation of the above three factors may affect unfavourably the development and retraction of the clot. Rest- lessness or movement of the patient, or injudiciously rapid intravenous infusion may raise the blood pressure. Retraction of the inner coat may be prevented by arteriosclerosis of the vessel's wall or by its fixation in thick scar tissue, whilst the coagulability of the blood may be diminished by vitamin deficiency, by starvation or as the result of repeated haemorrhages. These three last are especially noteworthy, because they may all three be present under the starvation regime. Under normal conditions the coagulability of the blood is increased after a single haemorrhage (Moon, I94I), whilst blood transfusion has a similar effect.

\section{Methods of Treatment and Results}

Until recent years the recognized method of treatment of peptic ulcer haemorrhage was medical, comprising a starvation, morphia, gradually in-? creasing diet regime. Later blood transfusion was added, at first given rapidly, then by the slow continuous drip method of Marriott and Kekwick (1935). Surgery was undertaken only for those cases which were despaired of under medical treatment, and, not unexpectedly, was attended by a huge mortality.

The results of this treatment have been widely discussed and figures for mortality reported from all parts of the world. They showed a wide variation, ranging from 4.2 per cent. (Crohn and Lerner, New York, I939) to $5^{8}$ per cent. (Ross, Melbourne, 1930), but the average figure lay between 9 and 12 per cent. The following are representative :-

Mortality Statistics. Starvation Regime London, Aitken $\quad$. $\quad$ I934 I I per cent.

Birmingham, Bulmer .. 1932 10.7 ", ",

Denmark, Christiansen I934 7.9", ",

Norway, Frostad . $1934 \quad 9.4$ " ",

Sweden, Mossberg . $1933 \quad 9.0$ " ,

Germany, Umber . $1935 \quad 9.5$ " ",

Boston, Jankelson .. 1938 9.0 " ",

San Francisco, Goldman 1937 II.5 ", ",

This method of treatment therefore has a very considerable mortality. It is furthermore open to the grave objection that a number of deaths and 
considerable morbidity result from the treatment rather than from the disease. Chest complications are largely responsible for this whilst Meulengracht (1937) vividly describes the miseries of a patient who died from ascending parotitis after 8-10 days under strict medical regime.

The reversal of the starvation policy in the treatment of ulcer haemorrhage was first suggested by Andresen in 1927. His routine included the twohourly administration of a gelatin-water mixture but he did not publish the results of his method until 1939, when he reported a mortality rate of 2.5 per cent. in 120 patients. It remained to Meulengracht (1934) to produce a profound and widespread impression by his advocacy of an immediately liberal diet in the treatment of peptic ulcer haemorrhage. He advocated three-hourly feeds of a light, soft diet including tea, cocoa, bread and butter, a variety of soups, minced meat and fish, representing about 2,300 calories, together with alkalis, extract of hyoscyamus and iron. The worse his condition, the greater the importance laid on the patient taking his feeds; from the first day he was allowed to move about in bed. In 1937, Meulengracht reported 368 consecutive cases of haematemesis and melaena from peptic ulcers, acute and chronic, treated on these lines, with a mortality of I.3 per cent.

These claims have been fully substantiated by subsequent writers. Witts (1937) in a most excellently reasoned article states that patients so treated look, feel and do much better than any previous series he has seen. The following figures, from various sources, are representative of the results obtained :-

\begin{tabular}{|c|c|c|c|c|}
\hline $\begin{array}{l}\text { Mortality Statistics. } \\
\text { Regime }\end{array}$ & Promp & & Fee & ding \\
\hline $\begin{array}{c}\text { Jones; St. Bartholomew's } \\
\text { Hospital }\end{array}$ & 1030 & 2.0 & per & cen \\
\hline Lineberry, Birmingham .. & 1937 & 3.6 & 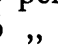 & \\
\hline Scott, Glasgow ${ }^{2}$ Luke's & 1940 & $3 \cdot 3$ & ", & $"$ \\
\hline $\begin{array}{l}\text { Hospital } \\
\text { Thorsted, Detroit }\end{array}$ & $\begin{array}{l}1941 \\
1942\end{array}$ & $\begin{array}{l}2.0 \\
2.8\end{array}$ & $"$ & ", \\
\hline
\end{tabular}

A comparison of the results shown in these two tables leaves little doubt as to the efficacy of the prompt feeding regime. The following suggestions have been put forward as reasons for its success as compared with the starvation regime :-

I. Peristaltic action is diminished when the stomach contains food.

2. Food neutralizes the gastric juices which therefore do not come into contact, undiluted, with the ulcer.

3. The deleterious effects of deprivation of fluid, food and vitamins on shock, clotting of blood, blood regeneration and convalescence are avoided.

4. The patient's morale is much improved.

Thus the most effective medical treatment at the present time is a combination of prompt feeding with a moderate calorie, high vitamin value diet together with iron, alkalis, antispasmodics, moderate doses of morphia and blood transfusion by the drip method. In the last ten years with the development of this treatment, the mortality rate of peptic ulcer haemorrhage has been very much reduced, in fact to about 3 per cent. It is rare now, therefore, for a patient to die of this condition and there is an inclination to accept the remaining mortality as inevitable. Meulengracht (I937) voices this by stating that with so low a mortality the question of operation does not arise.

When figures for surgical treatment of this condition in past years are quoted with mortality rates up to roo per cent. (Hurst and Ryle, I937), there is a tendency to take the view that these cases represent the complete failure of surgery in haemorrhage from gastric and duodenal ulcers. It can be argued with greater truth that, as surgery was invoked only as a last desperate venture, the failure lay primarily in not recognizing the severity of the haemorrhage earlier in its course, before the patient had entered the stage of irreversible shock.

Is it possible to predict which cases are likely to die from peptic ulcer haemorrhage ?

Statistics from many sources have shown that ulcer haemorrhage is rarely fatal (a) in women, (b) under the age of 45 , (c) from acute ulcers, and that in fatal cases arteriosclerosis is a common post-mortem finding (Blackford and Allen, I942; Thorsted, 1942). Cullinan and Price (1932) showed that a recurrent haemorrhage is much more likely to be fatal that a first haemorrhage, although Blackford (1942) shows that first haemorrhages are responsible for 75 per cent. of the fatalities. From these facts it appears that there is a group in which the mortality is considerably higher than the average figure, namely, in men (i), over 45 years of age (ii), known to have chronic ulcers (iii), which have previously caused gross haemorrhage (iv), the outlook being further worsened by the presence of arteriosclerosis. The writer is of the opinion that the mortality figures in this group would be of very considerable interest and may well prove to be in the region of 30 per cent.

Can anything be learned by division of the cases into two groups, mild and severe? Various criteria have been put forward to differentiate the two. The earlier suggestions such as a red cell 
count below $2,000,000$ per c.mm. or a haemoglobin below 40 per cent. have been shown to be unreliable owing to the variability of haemodilution after haemorrhage. Such cases are now, in any case, routinely transfused, which further vitiates the result. Witts (1937) regards as serious any case in which the blood urea rises above 75 mgm. per cent., but this has not been widely followed up. Recent methods of examination of the blood promise more reliable information as to the severity and progress of the case. They include determination of the blood specific gravity by the hanging-drop method of Barbour and Hamilton (I926), blood haematocrit readings and the estimation of plasma protein values. Scudder (I939) showed that in conditions of massive haemorrhage the blood specific gravity falls from the normal 1056.6 to 1040 or less. From these or similar estimations new criteria may emerge by which it will be possible early in the event to differentiate between mild and severe haemorrhage.

Hinton (1939) proposed a therapeutic test. $\mathrm{He}$ suggested that, if the haemoglobin level and the blood pressure remain low after the administration of two blood transfusions of $500 \mathrm{cc}$. each, a large vessel has been involved and surgery is indicated.

Has surgery then a place in the treatment of ulcer haemorrhage ? Firstly, let us agree that, as a last resort where prolonged haemorrhage has failed to respond to the best medical treatment, surgical intervention holds out very slender hope. If, however, this same case be brought to operation earlier in the course of the haemorrhage the outlook is very different. Finsterer (1939), who first advocated immediate operation for massive ulcer haemorrhage reported a mortality of 5.I per cent. in 78 cases operated upon within 48 hours of the onset of haemorrhage. After 48 hours his mortality rate rose to 29.7 per cent. GordonTaylor (1935) in similar circumstances records a mortality of 19 per cent. in 32 cases. Rankin (1939) is of the opinion that surgery is advisable in massive haemorrhage from a known chronic ulcer which has failed to respond to medical treatment, as well as in recurrent haemorrhage, but most writers avoid absolute indications stating merely that operation should be considered.

On the surgical side advances have been made in the fields of rapid and controlled shock therapy, in anaesthesia and in post-operative care. The operation of choice is partial gastrectomy with removal of the ulcer ; if the patient's condition does not permit this, the ulcer is exposed by opening the stomach or duodenum and haemorrhage is controlled either by sutures passed under an obvious bleeding vessel, or by mattress sutures underrunning the whole ulcer. The chief dangers are shock and haemorrhage, ileus and postoperative chest complications. Rapid and continuous blood transfusion, the ${ }^{-}$indwelling gastric or jejunal suction tube and cyclopropane anaesthesia with its smooth induction, rapid elimination and absence of post-operation vomiting, together with chemotherapy and suction-bronchoscopy if necessary, have done much to diminish these risks. Provided, therefore, firstly that the patient is in other respects a good anaesthetic risk : secondly that he has not entered an irreversible state of shock, and thirdly that a competent surgical team, anaesthetist and blood transfusion facilities are immediately available, surgery holds out good hope. The problem revolves round the possibility of bringing the serious case to operation during the early stage of the haemorrhage, that is, within 24 or perhaps 48 hours of its onset.

\section{Conclusion}

The treatment of haemorrhage from chronic peptic ulcers of the stomach and duodenum is without doubt medical. Since the introduction of the prompt feeding regime by Meulengracht results have been encouraging and the mortality has been greatly reduced. Deaths are therefore uncommon but they are none the less distressing.

If the fatal tendencies of the serious cases can be foretold during the early stages of the haemorrhage, surgery, in otherwise healthy individuals, holds out good hope. In a certain group of cases the mortality under medical regime remains high, namely in recurrent haemorrhages in men over 45 years of age known to have chronic ulcers, especially in the presence of arteriosclerosis. In this group, provided that the patient is otherwise healthy and that competent surgical, anaesthetic and transfusion teams are at hand, operation is indicated within $24-48$ hours of the onset of haemorrhage.

In first haemorrhages, which are responsible for a high proportion of the fatalities in this condition, surgery has been advocated, not unreasonably, in cases of known chronic ulcer which, in spite of full medical treatment, proceed to bleed (Rankin). In general, however, we are as yet unable to form an opinion early in the disease of the potentialities of such cases. With further research, perhaps by a combination of blood examination and of a therapeutic test, we may be able to pick out the serious cases within 24 hours or less of their onset. Surgery may then be able to play a further part in the reduction of the mortality from ulcer haemorrhage. 


\section{PERFORATION}

\section{General Consideration}

Since Mikulicz first closed a perforated ulcer in 1880, the treatment of perforation of peptic ulcers has been the subject of perennial discussion and enquiry. More especially has this been so in recent years because the incidence of the condition has been shown to be increasing, whilst in spite of all efforts the mortality in the last ten years has shown little change, remaining for general hospital series in the region of 20-25 per cent. For the patient, perforation is one of the most agonizing catastrophies; for the surgeon, it is especially a challenge, because the majority of his cases are useful members of the community in young middle life.

Historically, the death at the Court of Louis XIV, of the Duchess of Orleans, daughter of King Charles I of England, from a perforated gastric ulcer was most vividly described by Madame de la Fayette, and was epitomized by Bossuet in these famous words: ' $O$ nuit effroyable, où retentit tout à coup, comme un éclat de tonnerre, cette é tonnante nouvelle: Madame se meurt! Madame est morte!' (Bossuet, r760).

The first successful operation for closure was performed by Heussner in 1892 (Kriege, I892). Braun (1897) introduced the addition of gastroenterostomy, whilst von Haberer (1919) advised partial gastrectomy in suitable cases, a procedure now popular in certain clinics on the continent: It has long been known, however, that all cases do not necessarily die without operation. Hall (1892) reported six cases of spontaneous recovery, whilst Blackford (1942) mentions 28 cases treated by gastric suction through a Levine tube, without operation, with three deaths. Occasional cases have been similarly treated in this country, with comparable results (Turner 1945).

It appears to be impossible to estimate satisfactorily what percentage of ulcers perforate, but there can be no doubt that the incidence of perforation has greatly increased in the last 20 years (de Bakey, 1940). Furthermore, from being mainly an affection of women (Brinton, $1856: 68.4$ per cent. females) it is now largely restricted to men (92.2 per cent., collected figures, de Bakey ; 90 per cent., Southend General Hospital). The diminished incidence of acute ulceration in young women accounts in part for this change, but for the higher incidence in men some factor in our everyday life would appear to be responsible. Much evidence points to increased tobacco smoking as the important factor. Bager (1929) draws interesting parallels between the annual tobacco consumption and the perforated ulcer incidence in Sweden. Records of the percentages of smokers and non-smokers developing perforations would be of considerable interest.
All age groups are affected, from early infancy (two days, Stern, 1929) to old age (84 years, Kelly, 1939), but the majority of cases occur between the ages of 20 and 50 years. Judine (1939) shows that the average age of duodenal perforations in his series was 32 years, whilst that of gastric perforations was 46 years. A slight seasonal variation was noticed by him, possibly due to an increase after influenza epidemics.

There has been much discussion as to whether perforation of gastric or duodenal ulcers is commoner. Widely differing figures have been published. It would appear that -this divergence of opinion has arisen in part at least, from the difficulty at operation of defining the exact position of the pylorus. It is a common experience to find that a perforation, first thought to be pyloric (and therefore gastric), on closer inspection proves to be duodenal. In 54 cases at the Southend General Hospital six were gastric, giving a ratio of $8: I$ in favour of duodenal perforations.

Judine (1939) from careful macro- and microscopical examination of stomachs resected for perforation states that 87.5 per cent. of 928 cases were duodenal. Other recent figures bear out this preponderance (de Bakey 1940).

Controversy has raged also over the question, is it the acute or the chronic ulcer which perforates? At operation, with the whole area grossly oedematous, it may be difficult to establish the exact nature of the underlying ulcer. The patient's previous history is therefore a more accurate guide and should be enquired into a second time during convalescence. In the agony of perforation a man may well forget earlier comparatively trivial attacks of indigestion. In 54 cases at the Southend General Hospital 38 gave a definite history of attacks of dyspepsia (70 per cent.). Higher figures are common (90 per cent., Graves, 1933; 95 per cent., Judine, 1939). Walton (1930) states that of 42 cases which came to autopsy, 4I showed chronic ulcers. Chronic ulcers are therefore responsible for the majority of perforations, but without doubt, acute ulcers can perforate, and, in so doing, produce their first symptom.

The only point of agreement amidst these controversial matters is that it is the anterior ulcer which perforates. Posterior ulcers penetrate but rarely perforate. They perforate only $(a)$ into the lesser sac, which is rare, as the sac is usually obliterated near the ulcer by adhesions, or $(b)$ by involving the superior surface of the stomach or duodenum, and so the general peritoneal cavity.

The diagnosis is not as a rule difficult. Diminished liver dullness, elicited with the chest raised, is an important sign. It can frequently be confirmed by an X-ray taken with the patient sitting, when a crescent of gas is seen under the diaphragm. 
A duodenal perforation not infrequently simulates acute appendicitis, owing to escape of duodenal content down the right paracolic gutter; this provides one of the commonest sources of error in abdominal diagnosis. It is of interest that although the inflammation produced by perforation of peptic ulcers is in close proximity to the diaphragm and is a fruitful source of subphrenic abscess, pain referred to the shoulders is not common (de Bakey, 1940).

Moynihan (1928) pointed out that patients suffering from perforation are rarely in a state of true surgical shock, as shown by rise of pulse rate and fall of blood pressure. He refers to their state as one of prostration. Soutter (194I) states that only 20 of his series of 335 cases showed signs of true surgical shock. If true shock is present the prognosis is grave.

The bacteriology of the peritoneal exudate has been extensively studied and has been shown to be valuable in prognosis. It is now also of considerable value in influencing the choice of chemotherapy. In the first six hours the fluid is often sterile, in the second six hours it is usually, and thereafter always, infected. The sterility in the early stages is probably due to the gastric acidity. As the acid is neutralized after perforation, so the bacteria are able to multiply. The prognosis is more serious in infected cases. Trout (1935) advocated a study of the bacterial content of the mouth, teeth and throat, pointing out that the bacteria in the stomach will correspond to those in the mouth. This bears out the clinical observathat the prognosis of a perforation in a patient with dental sepsis is grave.

\section{Treatment}

The surgical treatment of a perforation of a peptic ulcer is only an incident, though a major incident, in a full course of medical treatment.

During the last six years the following routine has been developed in the treatment of perforations at the Southend General Hospital :

\section{(I) Pre-operative}

As soon as the diagnosis has been made morphia, gr. $\frac{1}{4}$, or in robust individuals, gr. $\frac{1}{3}$, is given. A Ryle's tube is then passed through the nose to lie exactly in the lowest point of the stomach. The patient is turned and made to lie on his left side, so that any further escape through the perforation is only gaseous. The stomach is then emptied by suction through the Ryle's tube. If solid food is present which cannot be aspirated through a Ryle's tube, a small stomach tube, size 12 or $14 \mathrm{E}$, replaces it. An intravenous drip infusion is then started, most conveniently into a vein in the middle of the left forearm, the patient lying on his left side. The fluid administered at first is plasma, as being near in composition to the fluid lost into the peritoneal cavity. It is continued later with normal saline and 5 per cent. glucose, or by $\frac{1}{5}$ normal saline with 4.3 per cent. glucose according to the estimated needs of the patient. The stomach is kept empty by frequent aspirations, the mouth is cleaned, and, with the drip running, the patient is given 45 minutes' rest. If further morphia is thought necessary, small doses are injected without disturbance into the drip near the vein.

Although the average case is not suffering from true surgical shock, after such treatment he presents a very different picture. In place of agonized anxiety he shows a drowsy, reassured indifference. A considerable rise of blood pressure has on occasion been observed, but, in all cases, the mouth is clean, the stomach empty, the blood chemistry partially righted and the menta! condition changed beyond recognition.

\section{(2) Operative}

The patient is brought to the theatre with his eyes covered, the Ryle's tube in his stomach and the intravenous drip running. Throughout the operation the stomach is aspirated at short inter- 8 vals by the anaesthetist.

Local anaesthesia, consisting of an upper abec dominal field block with $\frac{1}{2}$ per cent. novocain (without adrenalin), has been the anaesthetic of choice in this series. In exceptionally muscular or nervous cases this has been supplemented with cyclopropane.

The incision is made through the inner margin of the right rectus, centred one half inch to the right of the mid point between the umbilicus and the sterno-xiphoid junction, that is, over the surface marking of the pylorus, and is of the shortest convenient length. An average is $3 \frac{1}{2}$ inches. Escape of gas is looked for. Fluid is removed from the peritoneal cavity by suction and the liver margin is raised with a Deaver's retractor in the right upper part of the incision, held by the assistant's right hand. The pylorus now lies exposed in the centre of the wound, the stomach being empty and flaccid. A gauze strip is placed on the pylorus and, with the index and middle fingers of the left hand on this gauze, the pylorus is retracted to the patient's left. The perforation is thereby brought into view.

Without moving the left hand three sutures are passed through the whole thickness of the duodenal wall, one above, one through and one below the perforation. A suitable piece of omentum is brought up and laid within the sutures, which are then tied, thus firmly closing the perforation. Both catgut and fine silk have been used for these sutures. 
Fluid is further removed by suction from the accessible parts of the abdomen which is closed without further manipulation of any kind. In the earlier part of this series closure was effected by buried interrupted sutures of No. 8 plaited silk, including all layers except the skin. The results left room for improvement ; wound infection and separation of the skin edges were not uncommon. A number of stitch sinuses resulted which were troublesome, but were easily dealt with by the immediate removal, under local anaesthesia, of the offending sutures. Other methods have been used, including strong silk, linen thread and wire through all layers including the skin, as in the repair of a burst abdomen. These wounds are strong, heal well, but produce unsightly scars.

Drainage of the abdominal cavity has not been employed in any case of less than 12 hours' duration. Drainage of the wound has been carried out in an increasing number of cases in view of the frequent occurrence of fluid collections. It seems a rational procedure. After closure the wound is covered with an Elastoplast dressing which seals it completely. No bandage or binder is used, in order to be certain that chest expansion is not impeded.

\section{(3) Post-operative}

The patient returns to bed with the Ryle's tube still in his stomach and the intravenous drip running. Being conscious, after only local anaesthesia, he is placed immediately in Fowler's position and at hourly intervals he is made to move his arms and legs, to breathe deeply and, with his hand firmly supporting his wound, to cough. Within 48 hours he is expected to sit forward without assistance and to move down the bed and back for his pillows to be arranged. Morphia is given in small but repeated doses into the intravenous drip (gr. $\frac{1}{8}-\frac{1}{6}$ ). In the early stages in order to lessen the pain caused, the patient does his exercises 30 minutes after an injection of morphia. His mouth is cleaned every two hours, but for 48 hours he is allowed to swallow only sips of clear fluid. These are immediately aspirated through the Ryle's tube by which means the stomach is kept empty and at rest.

Aspirations are continued until the fluid obtained from the stomach is clear and auscultation of the abdomen shows that bowel sounds have returned. This occurs usually in $36-48$ hours, when the Ryle's tube is removed. During this time the patient receives 5 pints of fluid intravenously each 24 hours. For the most part this consists of $\frac{1}{5}$ normal saline with 4.3 per cent. glucose ; to this are added vitamins $B$ and $C$ in full doses, chemotherapy, and at least I pint of blood or plasma. More recently a sterile solution of amino acids in the form of a casein hydrolysate solution has been added to supply, at least in part, the patient's protein requirements.

Physical signs of poor aeration of the bases of the lungs has been a constant finding. If signs of collapse of an area of lung develop the patient is put on the 'stir-up regime' (A.M.A. Subcom. on Anaesth., 1942). He is made to move his arms and legs, to breathe deeply and to cough every I5 minutes. Firm percussion over the affected area has been tried. If the signs of collapse are not considerably improved in six hours, suctionbronchoscopy is performed.

Chemotherapy. In the early part of this series no chemotherapy was used. Later, intramuscular sulphapyridine was given to those cases which showed evidence of respiratory infection. Recently soluble sulphathiazole has been given routinely intravenously (2 gm., followed by I gm. fourhourly) the course being completed by mouth after the infusion has been discontinued. Penicillin has not until now been available.

Diet. After 48 hours, bowel sounds being present and stomach aspirations clear, two-hourly feeds are started together with alkalis, antispasmodics and phenobarbitone in sufficient dose to keep the patient restful. Alternatively, if the patient has tolerated his nasal tube well, it is reinserted into the stomach and a milk drip is started. This forms the start of a full course of medical treatment. It is needless to say that smoking is strictly prohibited.

Owing to bed shortage patients in this series have been allowed home in two to three weeks to complete their treatment at home.

\section{Discussion}

Although patients after perforation are, as Moynihan said, in a state of prostration rather than of true surgical shock, there can be no question that one to two hours spent in preoperative preparation effects a great improvement in their condition. Provided that no further leakage is permitted into the peritoneal cavity, the writer is of the opinion that this time is time well spent. Leakage is prevented by aspiration of the stomach content and by turning the patient on to his left side. By this means any remaining stomach content lies to the left, in contact with the greater curvature, and cannot escape through a perforation on the lesser curvature, at the pylorus or in the duodenum. Furthermore, at operation, the stomach is empty and flaccid.

Local anaesthesia is preferred because by its means the cough reflex is never lost and the patient, being conscious throughout, is able to be propped up at once on return to bed, to move, to breathe deeply and to cough. If, on account of restless- 
ness, failure of relaxation or the presence of a gastric perforation away from the pylorus, local anaesthesia is unsatisfactory it is supplemented by general anaesthesia. Cyclopropane is the anaesthetic of choice owing to smoothness of induction, rapid return of consciousness and absence of post-operative vomiting. It has the further great advantage that within a few hours the patient has lost all feeling of having been anaesthetized.

In this series the chances have been 8 to $\mathrm{I}$ that the perforation would be in the first part of the duodenum. The incision has accordingly. been made through the inner margin of the right rectus muscle, centred over the pylorus. In most cases, a length of $3 \frac{1}{2}$ in. has proved ample. The incision is placed to the right of the midline for these reasons, (a) it is placed directly over the pylorus, (b) a few fibres of the rectus muscle left on the inner side of the incision add strength to the closure, and (c) the resulting scar does not impede subsequent surgery should this be necessary. If difficulty is encountered the incision is at once prolonged.

The method of closure of the perforation described is the simplest and causes the least possible trauma. No exteriorization of the stomach or pylorus, and no further exploration of the abdomen has been permitted. The object of the operation has been solely to close the perforation. For this reason neither gastro-enterostomy nor partial gastrectomy has been performed. It is impossible to cause stenosis by the application of an omental plug.

Practical, rather than theoretical evidence has yet to be produced that closure by an omental plug is more likely to be followed by persistence of the ulcer than other methods. In either case the ulcer heals by granulation, and so by scar tissue. Admittedly this may be slightly less in amount if the size of the ulcer is diminished by suture. At the same time, sutures introduce tension and so more fibrosis.

Strong silk and through and through sutures were used in closure of the wounds in order to give the strength particularly needed for early movement, breathing exercises and coughing. The method used prevents efficient wound drainage. The penalty has been some increase of wound infection.

In the post-operative treatment morphia has been used freely, but in small doses. Used judiciously, the patient being stimulated to move, breathe and cough every hour, the writer holds the view that morphia can help to prevent rather than to promote chest complications. The immediate institution of movements and exercises is of the first importance in the prevention of chest complications.

Rest. The cause of the condition having been, as far as possible, removed at operation by the closure of the perforation, the acutely inflamed stomach is kept at complete rest until it shows a return of function. This is achieved by continuous suction or by repeated aspirations through the Ryle's tube which is maintained until (a) the fluid aspirated from the stomach is clear, and (b) auscultation shows that intestinal peristalsis has recommenced. Forty-eight hours is an average time. Even without fluids by mouth considerable quantities of fluid may be aspirated from the stomach, having reached it by regurgitation from the duodenum or by being poured out from the inflamed stomach wall. Fluids given by mouth during this time only tend to increase this accumulation, to stimulate an inflamed organ and possibly to produce vomiting which, at all costs, must be avoided.

Fluids. For 48 hours or more under this regime the patients gastro-intestinal tract is kept entirely at rest. During this time therefore he must rely entirely for his intake on his intravenous infusion. As far as is possible this should supply all his requirements. Fluids are given according to the patient's needs, 5 pints being an average daily allowance, but this may be increased if the patient is dehydrated. Plasma is given initially, but thereafter the standard fluid used in this series has been $\frac{1}{5}$ normal saline with 4.3 per cent. glucose which supplies the patient's water, salt and glucose requirements (Naunton Morgan and Avery Jones, 1938). To this are added full doses of the short term vitamins $B$ and $C$ and, as already mentioned, chemotherapy. The protein requirements have been in part met by the inclusion of 1 pint of plasma or better, of whole blood each 24 hours. Recently the protein requirements have been more fully supplied by the addition of amino acids in the form of a sterile solution of casein hydrolysate (Gaunt, 1943). Much research is being carried out into the fascinating field of protein requirements in health and disease. For instance, Croft and Peters (1945) have shown that methionine is particularly in demand for tissue repair. Such work may bear fruit in the near future in the production of a fluid synthesjzed to contain all the requirements for metabolism, which may be of the greatest value in helping the patient in his return to health.

Chemotherapy. The two chief causes of death in this condition are (I) peritonitis and (2) lung complications (57.2 per cent. and 20.8 per cent. respectively of $95^{2}$ deaths ; de Bakey, 1940). Both are bacterial in origin. There is good reason, therefore, for the routine use of chemotherapy. 
In this series the drug of choice has been sulphathiazole, the soluble form being used in the intravenous drip, the course being completed by mouth after the drip has been discontinued. Penicillin may be valuable. From present knowledge, a combination of penicillin and sulphathiazole may well prove to be a very potent weapon against infection.

Medical Treatment. It cannot be over-emphasized that the surgical treatment of a perforated peptic ulcer is only a prelude to a full course of medical treatment. Early in the convalescence, therefore, a physician is consulted with regard to medical treatment which consists essentially of a gradually increasing diet of frequent milk feeds; together with alkaline powders, antispasmodics and sedatives in sufficient dose to make the patient restful. Phenobarbitone is extremely useful in this respect. When the patient is convalescent he is transferred to the care of the physician who undertakes the further treatment. After three months the patient returns for a routine X-ray examination, subsequent treatment depending on its findings. In 1,525 cases treated by closure with an omental plug collected from the literature by de Bakey (1940) more than half remained symptom-free ; the remainder developed subsequent ulcer symptoms, and 17 per cent. of the total required further surgical treatment. From these figures there is therefore a more than 50 per cent. chance of cure following simple closure of a perforation. Strict medical treatment will improve this chance.

\section{Summary}

The key to success in the treatment of perforation of peptic ulcers still lies in the hands of the general practitioner in the shape of early diagnosis.

Surgical treatment is the prelude to a full course of medical treatment.

One to two hours are well spent in pre-operative preparation.

Local anaesthesia supplemented if necessary by cyclopropane, is the anaesthetic of choice.

The operative procedure should be the minimum necessary to close the perforation securely.

Drainage of the peritoneal cavity is rarely necessary in cases of less than 12 hours' duration.

Chemotherapy should be used routinely.

Early movements and exercise are of the greatest importance in the prevention of chest complications.

Morphia, judiciously used, can prevent rather than promote chest complications.

Over $5^{\circ}$ per cent. of cases of perforation subsequently remain symptom-free. For those cases which subsequently develop symptoms, further treatment should be decided upon after due consideration, not at the time of perforation.

\section{GARGINOMA}

Since early last century it has been recognized that carcinoma of the stomach may be associated with a chronic gastric ulcer. At necropsy of patients dying from carcinoma of the stomach unmistakable signs have from time to time been found of the presence of a chronic gastric ulcer which have been confirmed by a long history of ulcer symptoms. The growth has usually been too advanced to state that it arose from the ulcer, but appearances have been suggestive. With the development of gastric surgery specimens were obtained showing carcinomata arising obviously in the edges of chronic ulcers, a picture more recently seen in vivo by means of the gastroscope. Histologists have gone further by showing the presence of carcinoma in the edge of ulcers which to all macroscopic appearance were benign.

In I909, MacCarty aroused widespread discussion by his statement that 68 per cent. of the gastric ulcers resected at the Mayo Clinic were associated with carcinoma, and that $7 \mathrm{I}$ per cent. of the resected carcinomata of the stomach were associated with chronic gastric ulcers. Moynihan (1926) lent some weight to these views by his statement that two thirds of his cases of carcinoma of the stomach gave a long history of dyspepsia. In the following years other views were expressed. Morley (1923), for instance, was frankly critical of the Mayo Clinic figures. In his series of 50 gastric ulcers thought macroscopically to be benign, histological examination showed five to be definitely malignant and a further six to be " possibly undergoing malignant transformation,' making a total of 22 per cent. certainly or possibly malignant. Cabot and Adie (1925) in a severely critical article showed the enormous variation in the published estimates of ulcer-cancer incidence and stated that many figures were entirely valueless owing to laxity in pathological diagnosis. In their own series of 56 cases diagnosed as simple ulcers, five proved to be cancerous ( 9 per cent.). Stewart (1925) reporting with meticulous histological criteria on 216 operation specimens, found 134 simple ulcers, 68 carcinomata and 14 ulcer-cancers. He concluded that 9.5 per cent. of the resected ulcers had therefore become malignant. Klein (1938) was completely sceptical and on most critical pathological grounds stated that ulcer-cancer is rare, the main difficulty being the establishment of the existence of a pre-existing ulcer. More recently Kirklin and MacCarty, jun. (1942), state that between ro and 12 per cent. of all gastric ulcers radiologically and macroscopically benign are in fact malignant. 
Finisterer (1939) states that 15.2 per cent. of 487 apparently benign gastric ulcers resected by him proved to be malignant. Allen and Welch (194I) state that of 69 ulcers resected by them as benign, 30 (43 per cent.) proved histologically to be malignant. Maingot (1942) found that in an operative series of 50 apparently benign ulcers in women, I I proved to be undergoing malignant change (22 per cent.).

These figures concern only cases treated surgically. They are likely to comprise therofore only the more severe chronic ulcers which have resisted medical treatment. Such operative series should by no means be confused with total series which contain all ulcers referred for treatment. In this latter group, Allen and Welch (I94I) report that of 277 cases originally diagnosed as gastric ulcer, 39 (I4 per cent.) finally proved to have cancer, whilst Judd and Priestley (r943) report on the subsequent history of 146 cases of gastric ulcer treated, apparently successfully, medically and followed up for at least five years. Of these 146 cases :

46.5 per cent. were cured.

1 5.8 per cent. well on medical regime.

4.8 per cent. ulcer shown to persist.

I 1 .o per cent. underwent operation for gastric ulcer.

9.6 per cent. developed carcinoma of stomach.

0.7 per cent. died from haemorrhage.

I I. 6 per cent. died from unrelated causes.

These figures are of considerable value. They show the subsequent course of a series of cases of gastric ulcer treated medically at the Mayo Clinic in which a follow-up study was possible, namely, that 46 per cent. were cured, that a further I5.8 per cent. remained well on diet, whilst 9.6 per cent. developed carcinoma of the stomach. It can be objected that a number of these carcinomata may have been unconnected with an ulcer. This may have been so, but the figures still show the incidence of carcinoma of the stomach in a series of cases of gastric ulcer. To sum up, therefore, (I) There is clear evidence that an ulcer which clinically, radiologically and even macroscopically appears benign, may in fact be malignant. The average percentage error in diagnosis is at least Io per cent.

(2) To prove the actual development. of carcinoma in a previously benign ulcer of the stomach is impossible. It would involve microscopy of the complete original ulcer in order to exclude the possibility of malignancy from the start. Circumstantial evidence is, however, very strong. The development of carcinoma in 9.6 per cent. of Judd and Priestley's series of 146 cases treated originally medically with apparent healing is noteworthy.

Therapeutic Test. In view of these facts a therapeutic test has been employed in the treatment of gastric ulcers. The diagnosis being established by clinical, radiological and gastroscopical evidence the patient is given a six weeks' course of strict medical treatment. The investigations are then repeated. If the ulcer is healed it is considered benign. If improved, but not yet healed, a further six weeks' treatment is prescribed and the investigations are repeated a third time. If still unhealed, the ulcer is probably malignant and surgery is indicated. If the ulcer is healed, the patient is allowed up but must continue his medical regime and must understand that recurence of the ulcer is possible and may be serious. He should report at once any return of symptoms and should return for further examination at threeand later six-monthly intervals. These examinations are physical, radiological and gastroscopical. Herein lies one of the most useful spheres of gastroscopy. By its means a recurrence of the ulcer or an irregular or nodular appearance at the site of the scar, indicating an early carcinoma, may be seen before either symptoms develop or radiological signs become positive. If surgical intervention is delayed until anorexia, wasting and a palpable mass are present, the chances of cure are tragically small.

In all such cases, therefore, it is of the utmost importance that routine examination be carried out at regular intervals. Any recurrence of the ulcer indicates ( $\mathrm{I}$ ) that it is malignant or (2) that even if the ulcer is benign, further medical treatment is unlikely to be successful. Recurrence is therefore an indication for surgery.

This therapeutic test combined with medical treatment is, however, by no means infallible. From the writer's experience it is often difficult to persuade a patient of middle or advancing years to attend for routine gastroscopy. He may feel well and be disinclined to see the importance of the repetition of an, at least, unpleasant experience. The writer has seen four such cases, apparently cured by medical treatment, return later with inoperable carcinomata of the stomach. Again, improvement under medical regime by no means rules out the possibility of malignancy, as Walters (1942) confirms. Furthermore, a carcinoma may develop rapidly between the routine examinations, whilst by no means all patients are capable of adhering to a regime which includes dieting and restraint from tobacco and alcohol. Lastly, Judd and Priestley (1943) in a careful follow-up survey show that the chances of cure by medical treatment are less than 50 per cent. 
Consideration. Under a medical regime there is, in the first place, the danger that the lesion, though apparently benign, may in fact be malignant. Errors of diagnosis even in the best hands are not uncommon and amount to some ro per cent. of all cases. Secondly, carcinoma may develop subsequently. In addition there are risks from haemorrhage, perforation, and stenosis, together only a 50 per cent. chance of cure.

In surgical clinics in which the mortality for partial gastrectomy for gastric ulcer is between 3 and 5 per cent. other considerations obtain. The risk of ulcer cancer is here greater than that of operation. The combined risks of haemorrhage, perforation, and cancer are much greater than those of operation in otherwise healthy cases. The treatment of chronic gastric ulcer in such cases should, therefore, it is held, be surgical. Exceptions are made in the case of (I) patients under 45 years of age, in whom the risk of cancer and of other serious complications is small, and (2) patients of advancing years or of infirmity from other causes in whom the risks of operation are great. In these groups medical treatment is advised but careful follow-up examinations must be carried out.

Summary. Evidence from a number of sources shows that, in the diagnosis of chronic gastric ulcer, with our present methods of examination even in the best hands there is an error of 10 per cent. At least $I$ in 10 of such ulcers is in fact malignant. Strong circumstantial evidence exists that others will become malignant, especially in patients over the age of 45 . The total risk from these two sources is without doubt more than ro per cent. and may well prove to be double that figure.

Where the mortality of gastrectomy is 20 per cent., the risk of ulcer cancer is of little significance in the choice between medical or surgical treatment. Where the mortality of gastrectomy is between 3 and 5 per cent. the risk of ulcer cancer becomes of very considerable significance. Under these circumstances the combined risks of haemorrhage, perforation, and cancer in patients of middle life materially exceed, in otherwise healthy individuals, the risks of gastrectomy. For such patients the treatment of choice is surgical, and only by means of surgery can the death rate from ulcer cancer be reduced.

In patients under the age of 45 , the risks of cancer as well as those of other serious complications are small. Medical treatment may therefore be advised but careful follow-up examinations are essential. Recurrence is an indication for operation.

In patients of advancing years and in those of poor health from other causes the risks of surgery are greater than those of complications and treatment should again be medical.

4. THE GOMPLICATIONS OF OPERATION FOR GASTRIG AND DUODENAL ULGER

For convenience of discussion the complications of operation for gastric and duodenal ulcer are considered in three groups, (I) immediate, occurring at or within 24 hours of operation, (2) intermediate, occurring during the remainder of the patient's hospital stay, and (3) remote, occurring subsequently.

\section{Immediate Complications}

I. Collapse under Anaesthesia. During the course of anaesthesia collapse may occur from shock, as in gross primary haemorrhage, from deficiency of oxygen which may be due either to an obstructed airway or to an actual failure of the oxygen supply, or from anaesthetic abnormalities. Shock is not a prominent feature in gastric surgery, and with good technique haemorrhage should be minimal. If either is anticipated, an intravenous infusion should be started before operation, and through it sufficient suitable fluid should be given to anticipate the onset of shock. Any blood loss is immediately replaced. At the conclusion of anaesthesia danger arises from the sudden drop in oxygen tension of the gases respired when the mask is removed. Sudden collapse from anoxia may follow. It is wise to bring the patient's B.L.B. mask and oxygen cylinder to the theatre and to continue the administration of oxygen forthwith.

During the period of recovery from anaesthesia there is a risk of aspiration of vomitus if any fluid is allowed to collect in the stomach. The use of cyclopropane for anaesthesia greatly shortens the period of recovery and almost rules out post-anaesthetic vomiting. The removal of all fluid from the stomach by means of frequent aspiration through an indwelling gastric suction tube removes the risk.

2. Haemorrhage. Severe primary haemorrhage should not occur in non-urgent gastric surgery. It is prevented by careful ligation of vessels. Any blood lost during operation lies either in Rutherford-Morison's pouch or under the left side of the diaphragm. An ooze, for instance, from the left part of the divided gastrocolic omentum collects near the spleen. If such collections are not carefully sought and removed at the close of operation they are likely to cause at least post-operative pyrexia and malaise, if not frank subphrenic infection. If infections and adhesions are to be avoided, haemostasis must be complete.

Reactionary haemorrhage is possible. If clamps 
are used, their release before the insertion of the anterior sutures of the anastomosis diminishes this risk. Anastomosis without clamps, however, combined with under-running the vessels in the gastric submucosa after dividing the seromuscular coats does everything that is possible to eliminate it. By this method any haemorrhage is immediately seen and is immediately controlled. That it is successful is shown by the fact that stomach aspirations after 12 hours are almost invariably free from blood.

3. Peritonitis. This may result either from soiling at the time of operation or from subsequent leakage from the anastomosis. For the first, the perfection of the aseptic method of anastomosis as advocated by O'Hara (1900), Wangensteen (1942), and by Pannett (I945) may entirely rule out operative soiling. If this is not attainable, proper preparation of the stomach, repeated aspiration during operation by means of the indwelling gastric suction tube, and good technique serve to minimize the chances of infection. Leakage from the anastomosis results either from faulty suturing or from stretching of the anastomosis by subsequent ileus. The use of three layers of sutures for the anastomosis, the outer layer consisting of interrupted sutures, is a very considerable safeguard at the time of operation.

Acute dilatation of the stomach and upper intestine which was a fruitful cause of tension on the anastomosis and so of leakage, is now almost eliminated by means of the indwelling gastric suction tube. This, a Ryle's tube, is passed through the nose two hours before operation and is then used to give the stomach a final wash out. It remains in situ during operation, when it enables the anaesthetist to keep the stomach empty, and after operation, when it serves to keep the stomach at rest, to prevent distension and to provide evidence of the stomach's return to function. It is removed only when aspirations are clear, when fluids taken by mouth are evidently passing on from the stomach and when auscultation shows the return of bowel sounds, in fact, usually after 36-48 hours.

After a gastro-enterostomy in a case of pyloric obstruction from a duodenal ulcer in a man of 68 , 17 pints of fluid were aspirated from the stomach by means of an indwelling suction tube in three days. The question of the nature of the fluids to be given intravenously to replace this loss was an interesting one. The patient recovered.

4. Vomiting and Acute Intestinal Obstruction. With the use of continuous gastric aspiration, vomiting after gastric operations has become rare. It may be troublesome after gastro-enterostomy. It is largely prevented by a well-planned stoma.
If it occurs, it is best treated by keeping the stomach empty and clean and by supplying the patient's fluid, glucose and vitamin requirements intravenously. Acute upper intestinal obstruction may occur at any time after operation. Its onset is dramatic. The patient collapses, his pulse rate is rapid, his eyes become sunken. The differential diagnosis from haemorrhage or general peritonitis may be impossible. Likely causes are a retrograde intussusception of the jejunum through the stoma, obstruction of a loop of jejunum passing through the aperture in the transverse mesocolon or rotation of the ascending or descending loops in an anterior anastomosis.

In a recent case after a difficult partial gastrectomy with an anterior Polya anastomosis for a large chronic gastric ulcer, the patient's progress for 20 hours was good. He then suddenly collapsed. His face was blanched, his eyes sunken, his pulse rate 160 ; he complained of pain in the epigastrium. The abdomen revealed only some epigastric tenderness. He died four hours later. Autopsy showed that the proximal loop, from the duodeno-jejunal flexure to the anastomosis, had fallen back and to the left behind the distal loop, and was acutely obstructed behind the mesentery of the jejunum forming the anastomosis. It thus formed a closed loop obstruction. This could have been prevented by the use of the $\mathrm{Y}$-shaped suction tube suggested by Wangensteen (1942), or by passing the tube at operation beyond the anastomosis into the proximal loop and subsequently using a second tube to aspirate the stomach.

5. Chest Complications. These are included advisedly in the immediate group. It is whilst the cough reflex and the respiratory movements are impaired that the foundations of almost all chest complications are laid.

Before operation it is important to rule out preexisting chest disease and to eliminate septic foci from the teeth. Throughout anaesthesia the airway must be unimpeded; this is best achieved by means of an intratracheal tube. The effects of anaesthesia should preferably be quickly dispelled so that the patient may sit up soon after his return from the theatre and the aeration of the bases of his lungs may be thereby improved. There should be no post-operative vomiting. In these two respects cyclopropane is invaluable.

The operation itself (I) must be sound and should not give rise to a severe peritoneal inflammation which will impair the movement of the diaphragm, and (2) the wound must be well and strongly sutured to allow early movement and exercises. Mimpriss (1944) emphasizes these points.

After operation, as soon as the patient becomes restless, morphia is given freely but in moderate 
doses, usually gr. $\frac{1}{4}$, at once followed by gr. $\frac{1}{6}$, repeated when necessary. Thirty minutes after his injection the patient is made to move his knees up and down as in cycling, to do deep breathing exercises and, with his hands firmly supporting his wound, to cough. At two-hourly intervals he is stimulated to move, to breathe and to cough up any sputum which may be present. Within 24 hours of operation he is expected to be able to sit forward by himself. This immediate movement regime is carried out largely by the nursing staff and involves a certain amount of bullying. If the exercises are carried out at first half an hour after injections of morphia, however, the pain is relieved. After doing his exercises and clearing his bronchi the patient sinks back into a sound and refreshing sleep.

In the opinion of the writer morphia used in this way prevents, rather than promotes, chest complications.

In the immediate post-operative period signs of poor air entry to the bases of the lungs are to be expected. Signs of an area of collapse must be carefully sought. If they appear, the full ' stir-up' regime (A.M.A. Subcom. on Anaesthesia, I942) is employed, the patient being made to move, breathe, and cough every 15 minutes. If the signs of collapse do not rapidly improve, suctionbronchoscopy is employed.

Provided that the lungs were previously healthy the response to this routine is satisfactory. In heavy smokers and in cases of chronic bronchitis the patient has difficulty and pain in coughing up thick, purulent sputum and sinks back exhausted after the effort. In such cases it is better to spend three weeks in pre-operative treatment for the cheat condition, than to spend three months coughing up a lung abscess and developing an incisional hernia.

6. Venous Thrombosis. Here, again, the foundations of trouble are laid during the period of immobilization. To prevent thrombosis, therefore, as soon as the patient is conscious he is made to move his arms and legs and, as soon as possible, he is expected to help himself up and down the bed whilst his pillows are rearranged. No kneepillow is permitted because :-

(i) It impedes the venous return in the popliteal veins during sleep, and

(ii) it prevents full movement of the legs during exercise.

Admittedly the patient tends to slip down from the full Fowler position whilst asleep, but this is counteracted by nursing care at least two-hourly, and the exercise involved in returning to the correct position is by no means harmful.

\section{Intermediate Complications}

1. Chest Complications. In this group, chest complications are of first importance. Mimpriss (1944) gives an excellent account of the complications he met in 100 consecutive cases of gastrectomy. He divides them into ( $\mathrm{I}$ ) bronchitis, (2) lobar atelectasis, and (3) lobular atelectasis. Bronchitis is the commonest post-operative chest complication and is usually an exacerbation of a pre-existing condition. It may cause the patient much pain in coughing but, by all possible means, he should be encouraged to cough up any sputum which may be present. Lobar atelectasis is rare, but its presence should be carefully sought at least twice daily. If it develops it is treated at once by the 'stir-up' regime previously described and, if necessary, by suction-bronchoscopy. Lobular atelectasis, as Brock (1936) pointed out, is a common post-operative development, the frequency of its diagnosis depending on whether the surgeon is looking for it. Mimpriss found it in 29 of his 100 cases, but shows that in 25 it proved to be mild and transitory. In the remaining four cases it progressed to more serious conditions, bronchopneumonia in three and empyema in one, but three of these cases were associated with serious infection below the diaphragm. In only one case uncomplicated by abdominal infection did the lobular atelectasis proceed to a fatal bronchopneumonia.

If signs of infection or atelectasis develop, chemotherapy is instituted immediately. Sulphathiazole, in the writer's experience, has been the drug of choice and is given in full doses intravenously or, later, by mouth. It has entirely altered the prognosis of infective chest complications.

2. The Wound. Wound infections result from lack of care at operation in allowing spillage of gastric content, in imperfect protection of the wound edges with impermeable packs or in incomplete haemostasis. Serous collections in the wound are more common with catgut but are less serious than with silk, which may cause a sinus until the offending stitch is removed. Provided that the wound is well and truly sutured a burst abdomen is a rare complication of operations for peptic ulcer. If it occurs it is the result of coughing combined with wound infection. Where the wound is covered with an occlusive dressing the first sign of separation of the wound edges is an out-pouring of fluid which soaks through the dressing. Its significance may not be immediately appreciated. Treatment consists of immediate resuture of the wound with strong silk or wire through all layers including the skin. Such wounds heal well but leave unsightly scars with ' cross- 
hatching.' Strong arguments can be advanced for the primary closure of the wound by this method in all cases of carcinoma, of chronic bronchitis and in elderly, or for other reasons, frail patients.

3. Subphrenic Abscess. This is a rare complication. It may arise from (I) subsequent infection of blood collections not removed at operation, (2) spillage of content from a badly prepared stomach, (3) the base of an ulcer left in the pancreas or liver, (4) injury to the common bile duct, (5) leakage from an imperfect anastomosis or (6) bursting of the duodenal stump. A duodenal fistula may follow. Such fistulae may heal spontaneously ; continuous suction is of the greatest value in treatment.

4. Diarrhoea. This is a common sequel of gastric operations and may cause the patient much inconvenience. It commonly starts five to seven days after operation and lasts three days or more. If it were due to absence of acid from the stomach, the administration of hydrochloric acid by mouth should be effective. If purely bacterial in origin, it might be susceptible to sulphaguanidine or sulphasuxidine. All three are useless. It appears more likely that the diarrhoea is due to an unaccustomed irritation of the small bowel, either physical or chemical, by food not previously partially digested in the stomach. This would explain the fact that the best treatment at present appears to be a temporary limitation of diet combined with kaolin and a soothing mixture. Predigested foods may prove to be of value.

5. Thrombophlebitis. With movement and stimulation of the patient from the earliest possible movement after operation, this complication is rare. When it has occurred it has resulted from intravenous therapy and has been caused by imperfect asepsis either at the time of insertion of the needle or cannula, or in subsequent care. If it occurs heparin, or possibly dicoumarin, should be used to prevent further thrombosis, the blood coagulation time being carefully checked.

6. The Anastomosis. In any non-urgent operation for a gastric or duodenal ulcer the stomach should be well prepared and its walls should be healthy. There is, therefore, no excuse for leakage. The greatest safeguard in this respect is a three-layer anastomosis, the outer layer consisting of interrupted, preferably mattress, non-absorbable, seromuscular sutures which take the weight of the jejunum, thus preventing any tension on the inner catgut layers. Great care is taken at the upper and lower angles of the stoma to see that the inner sutures are complete and reach well above and below the incisions in the jejunum and stomach.

A well-planned anastomosis should function satisfactorily as soon as the stomach and jejunum return to activity. Occasionally after gastrectomy the patient complains of discomfort after food in the left upper quadrant of the abdomen. This usually subsides within ten days and has been ascribed to jejunitis. X-ray confirmation of this diagnosis may be obtained in the shape of ' feathering' of the upper jejunum.

\section{Remote Complications}

I. Anastomotic Ulcer. This complication may follow any operation in which gastric and jejunal mucosa become continuous. Its incidence is highest in operations in which the bile is diverted from the anastomosis, as in the Roux-in-Y operation, now abandoned. This has been confirmed in animal experiments in which the bile has been diverted to the ileum, in which case ulceration is likely to occur throughout the jejunum.

After gastrojejunostomy the incidence of anastomotic ulceration has been estimated varingly up to 32 per cent. (Marshall, . 1942), occurring particularly in young men having a high gastric acidity. After partial gastrectomy, it was found to be not uncommon after operations in which the mucous membrane of the pylorus and of the pyloric antrum were not removed (Ogilvie, I938; Kiefer, 1942). It may occur after more complete gastrectomies but its incidence is rare. If it does occur it is probably an indication that an insufficient amount of stomach has been removed, leaving sufficient acid-producing area to produce further ulceration.

An anastomotic ulcer is situated on the line of the anastomosis or immediately beyond it in the distal loop of the jejunum. It has all the characteristics of a gastric or duodenal ulcer, is likely to be associated with inflammation and spasm of the anastomosis and is liable to haemorrhage, to perforation and, by adhesion to the transverse colon, to form a gastro-jejuno-colic fistula.

Clinically, if anastomatic ulceration is to occur, it does so usually within a year of the primary anastomosis. It gives rise to typical symptoms, namely, pain to the left of the umbilicus, severe and gnawing in character, not necessarily related to food, but making the patient afraid to eat and causing considerable loss of weight. The pain may make life a burden. Occult blood is constantly present in the stools. Frank haemorrhage may occur at any time. If perforation occurs, the anastomosis being posterior, the escaping fluid lies beneath the shelf of the transverse mesocolon and passes down to the left iliac fossa, where tenderness and rigidity are most marked. The upper abdomen is protected by the mesocolon and may be relatively little involved. 
In the presence of a chronic stomal ulcer, the overlying transverse colon is liable to be involved at first in adhesions, later in the actual ulcerative process. The results of the formation of a gastrojejuno-colic fistula are serious. The patient develops a persistent diarrhoea with the passage of undigested food in the stools, he has an unbearable hallitosis, loses weight rapidly, and may develop nutritional oedema. There are few states more pitiable. Barium taken by mouth may be shown to pass immediately into the colon, whilst a barium enema may at once outline the stomach. The latter is often better seen.

Treatment. The medical treatment of anastomotic ulceration has proved disappointing. Improvement and relief of symptoms may be obtained but, even with complete adherence to a medical regime, symptoms are likely to recur and the patient to become a semi-invalid. $\mathrm{He}$ is unable to work and his life revolves round his diet, his sleep, and his bowels.

Surgical treatment, on the other hand, offers a good chance of cure. The operation of choice is sub-total gastrectomy, removing a large proportion of the acid-bearing area of the stomach, and closing the jejunal stoma with or without resection.

If the gastro-jejunostomy has been done without a loop, the separation of the proximal portion of jejunum may be the most difficult part of the operation. If a loop is present, separation of the anastomosis may be much simpler. Great care must be taken not to damage the middle colic vessels. The jejunal opening may be closed most simply by repairing it transversely, in rather longer time by the method of Pauchet (1934) or, if necessary, by resection and end-to-end anastomosis. The jejunum distal to this closure is used for the subsequent anastomosis, which, in view of the necessarily wide resection of stomach, is best of the anterior Polya type. With good anaesthesia and transfusion facilities the mortality of this operation in skilled hands is low. Marshall (1944) quotes 62 cases with three deaths, representing a mortality rate of 4.8 per cent.

Haemorrhage from an anastomotic ulcer is treated as from a gastric or duodenal ulcer. The outlook of recurrent haemorrhages is poor; resection is advisable.

The serious results of a gastro-jejuno-colic fistula are not due to the loss of gastric content into the colon, but are due to persistent gastro-enteritis caused by faecal contamination of the stomach. The whole bowel is in a constant state of acute inflammation. This is proved by the striking improvement effected by a defunctioning colostomy. At a preliminary operation the hepatic flexure is mobilized and brought out as a Paul-
Mikulicz colostomy through a right-sided oblique or transverse incision. If the area of the fistula can be inspected with retraction, the whole area is seen to be grossly inflamed and oedematous. For a week or two after opening this colostomy the still inflamed intestine pours forth fluid faeces, and the skin around the colostomy may become red unless this possibility is carefully foreseen. The patient and his attendants may lose heart and feel that the colostomy was useless. With daily washouts, however, both from the colostomy and from the rectum, the distal loop of colon gradually becomes clean and contains only a small amount of fluid which has passed through the fistula. No further faecal contamination of the stomach occurs and gradually the inflammation of the whole intestine subsides, colostomy actions become fewer, and the patient's condition improves. He loses his hallitosis and oedema, his appetite becomes excellent, he puts on weight and feels vastly improved. It should be noted that the improvement after colostomy is not immediate.

Six to eight weeks after the preliminary colostomy, the second operation is performed. An intravenous infusion is maintained throughout the operation. The inflammation noted at the time of colostomy has subsided. The first problem is the separation of the colon. Only a small area of it is usually involved and can be dealt with simply by inversion. The bowel being defunctioned, little risk arises from this source. The remainder of the operation is as for an uncomplicated gastro-jejunal ulcer.

Ten days after the gastrectomy the spur of the colostomy is crushed, restoring the continuity of the colon, and three weeks later the colostomy is closed extraperitoneally, with careful inversion of its margins. Delayed primary suture has been found of much value in closing these wounds.

Objections to this routine of treatment are, firstly that it involves at least three months in hospital, secondly, that it involves the unpleasantness of a colostomy, and, thirdly, that it requires three stage operations. These are, however, the price the patient has to pay for safety in the shape of a greatly reduced mortality, as compared to that of the one-stage operation. There is no more grateful patient than a man who has been cured of a gastro-jejuno-colic fistula.

2. Post-gastrectomy Dyspepsias. The condition of patients after gastrectomy for gastric and duodenal ulcer has been the subject of much discussion. It is generally agreed that, for gastric ulcer, the results are almost uniformly satisfactory. For duodenal ulcer, after the Polya type of anastomosis occasional cases occur in which the patient complains of a feeling of distension soon after food 
and even retching and vomiting may occur. A barium meal in these cases usually shows that the anastomosis is lying transversely and that a considerable part of the meal has passed into the considerable part of the meal has passed into the proximal blind loop of the duodenum. Such patients often find that after a meal they have to lie down for a time, preferably on the left side, after which the distension is relieved and they feel well again. The discomfort may make the patient afraid to eat. This symptom tends to diminish with time as the patient learns to adjust his diet. It may be avoided by placing the stoma obliquely, proximal jejunum to lesser curvature, with the proximal loop brought up to the upper part of the lesser curvature well above the anastomosis. Food is thereby diverted into the distal loop of the jejunum and so, without obstruction, into 21 feet of small intestine. The effect may be increased by closing the upper half of the cut surface of the stomach, which acts as a valve, directing the food distally (Hofmeister, 1905). The results of this operation have proved satisfactory, the patients being subsequently well and able to eat, drink and smoke as they please, provided that the resection has been sufficiently radical in removing the acid-bearing portion of the stomach.

3. Post-gastrectomy Anaemia. Since the recognition of the fact that, provided the resection has been sufficiently radical, subsequent dieting is unnecessary, anaemias, both micro- and macroscopic, have been almost unknown. Occasionally administration of iron for a few weeks after operation may help the patient to restore his haemoglobin, but its continued administration is seldom necessary. The writer has yet to see a case of macrocytic anaemia following gastrectomy.

4. Incisional Hernia. The great cause of incisional hernia is wound infection. With good technique this should be rare. With the evolution of aseptic anastomosis it may be eliminated. In order to be able to move the patient immediately after operation and to make him do breathing and coughing exercises, a strong closure is essential. Buried interrupted silk sutures through all layers except the skin give the strongest possible closure. With this method of closure one can with confidence assure the patient that he will not damage his wound by coughing. Silk is, however, liable to cause sinuses which persist until the silk is removed. Catgut is not liable to sinus formation, but does not give such a strong closure.

\section{Summary}

In undergoing any operation for gastric or duodenal ulcer, the patient runs the risk of a number of complications. These may prove fatal or they may cause merely a hitch in the smooth progress of his convalescence. In either case with proper knowledge they should be largely avoidable.

In the prevention of chest complications which are the patient's greatest enemv, four factors are of prime importance :

I. Careful pre-operative preparation with special care to rule out pre-existing chest disease.

2. Good anaesthesia, allowing rapid return of consciousness and not being followed by vomiting.

3. Sound operative technique, preventing peritoneal soiling.

4. The 'stir-up' regime, which aims at rapid and complete re-expansion of the lungs. It further has the advantage of restoring the venous circulation and so of reducing the incidence of venous thrombosis. Lastly, the indwelling gastric suction tube has eliminated the danger of tension on the suture line caused by upper intestinal ileus.

In this field, above all, prevention is better than cure.

\section{BIBLIOGRAPHY}

I. HAEMORRHAGE

AITKEN, R. S. (1934), Lancet, r, 839.

ANDRESEN, A. F. R. (1939), Am. F. Digest. Dis., 6, 641.

BARBOUR, H. G., and HAMILTON, W. F. (1926), four. Biol. Chem., 69, 625.

BLACKFORD, J. M., and ALLEN, A. (1942), Ұ.A.M.A., 120, 81 r. BULMER, E. (1932), Lancet, 2, 720.

CHRISTIANSEN, T. (1935), Acta Med. Scand., 84, 374.

CROHN, B. B., and LERNER, H. H. (1939), Am. $¥$. Digest. Dis., 6, 15 .

CULLINAN, E. R., and PRICE, R. K. (1932), St. Barts. Hosp. Rep., 65, 185 .

FINSTERER, H. (1939), Surg., Gyn. Obst., 69, 291.

FROSTAD, S. (1934), Norsk. Mag. Laegevidensk, 95, 578.

GOLDMAN, L. (1938), Am. F. Surg., 40, 545.

GORDON-TAYLOR, G. (1935), Lancet, 2, 81 r.

HINTON, J. W. (1939), Ann. Surg., 110, 376.

HURST, A. F., and RYLE, J. A. (1937), Lancet, I, I.

JANKELSON, I. R., and SIEGEL, M. A. (1938), New Eng. F. Med., 219, 3.

JONES, F. A. (1939), B.M.F., 1, 915.

LINEBERRY, E. D., and ISSOS, D. N. (1937), South Med. Four., 30, 1228.

MARRIOTT, H. L., and KEKWICK, A. (1935), Lancet, $1,977$. MEULENGRACHT, E. (1934), Act. Med. Scand., 59, 375.

MEULENGRACHT, E. (1937), Munch. Med. Wchschrft., 40, 1565. MOON, H. V., et al. (194I), F.A.M.A., 117, 2024.

MOSSBERG, O. (1933), Hygeia., 95, 898.

RANKIN, F. W., et al. (1939), South. Surgeon, 8, 298. .

ROSS, K. (1930), M. F. Australia, x, 168.

SCOTT, L. D. W. (1940), Edinb. Med. Four., 47, 49.

SCUDDER, J. (J. B. Lippincott, 1940), Shock : Blood Studies as a Guide to Therapy.

THORSTAD, M. J. (1942), Surgery, 12, 964.

UMBER, F. (1935), Deutsch. Med. Wchnschrft., 61, 1265.

WITTS, L. J. (1937), B.M.F., 1, 847.

WOLDMAN, E. E. (1941), Am. F. Digest. Dis., 8, 39.

\section{PERFORATION}

AMA. SUB-COMMITTEE ON ANAESTHESIA (Am. Med. Ass. Press, Chicago, 1942), Fundamentals of Anaesthesia, 149.

BAGER, B. (1929), Acta Chir. Scand., Suppl. II, 64, 5. 
BI,ACKFORD, J. M. (1942), Ұ.A.M.A., 120, 825.

BOSSUET, Oraisons Funebres (Hachette. Boulevard, St. Germain, Paris).

BRAUN, H. (1897), Zentralb. f. Chir., 24, 739.

BRINTÓN, W. (I856), Brit. and For. Med.-Chir. Rev., 17, 159.

CROFT, P. B., and PETERS, Prof. R. A. (March 3rd, 1945), Lancet, 266.

DE BAKEY, M. (1940), Surgery, 8, 852 and 1028.

GAUNT (1943-44), Nutrition Abstracts and Reviews, 13, 501.

GRAVES, A. (1933), Ann. Surg., 98, 197.

HALL, W. W. (1892), Brit. Med. Four., r, 64.

JUDINE, S. (1939), f. internat. de Chir., 4, 219.

KELLY, M. W. (1939), Surgery, 6, 524 .

KRIEGE, H. (1892), Berlin Klin. Wchnschr., 29, 1244.

MIKULICZ, J. (1897), Zentralbl. f. Chir., 24, 69.

MORGAN, C. N., and AVERY JONES, F. (1939), Lancet, 2, 61 I.

MOYNIHÁN, SIRR BERKELEY (W. B. Saunders Co., 1926), Abdominal Operations.

SOUTTER, L. (194I), Surgery, 10, 233.

STERN, M. A., et al. (1929), Lancet, 49, 492.

TROUT, H. H. (1935), Ұ.A.M.A., 104, 6 .

TURNER, E. W. BEDFORD (March 31st, 1945), Brit. Med. Four., 457 .

VON HÄBERER, H. (1919), Wien, Klin. Wichnschr., 32, 413

WALTON, SIR JAMES (Arnold \& Co., London, I930), Textbook of the Surgical Dyspepsias, 64.

\section{CARCINOMA}

ALLEN, A. W., and WELCH, C. E. (1941), Ann. Surg., 114, 498. CABOT, HUGH and ADIE, G. C. (1925), Ann. Surg., 82, 86. FINSTERER, Prof. H. (1939), Proc. Roy. Soc. Med., 32, 183 .
JUDD, E. S., and PRIESTLEY, J. T. (1943), Surg. Gyn. Obst. KIR, 21 .

KIRKLIN and MacCARTY (1942), four. A.M.A., 210, 733

KLEIN, S. H. (1938), Arch. Surg., $37,155$.

MacCARTY, W. C., and WILSON, L. B. (1909), Am. four. Med. Sci., 138, 846.

MacCARTY, W. C. (1910), Surg. Gyn. Obst., ro, 449.

MAINGOT, RODNEY (1942), Post Grad. Med. four., 18, 93

MORLEY, JOHN (1923), Lancet, 2, 823

MOYNIHAN, SIR BERKELEY (W. B. Saunders Co., 1926) Abdominal Operations.

STEWART, Prof. M. J. (1925), Brit. Med. Four., 2, 882.

WALTERS, W. (1942), Arch. Surg., 44, 520.

4. THE COMPLICATIONS OF OPERATION FOR GASTRIC AND DUODENAL ULCER

A.M.A. SUBCOM. ON ANAES. (A.M.A. Press, Chicago, 1944), Fundamentals of Anaesthesia, i65.

BROCK, R. C. (1936), Guy's Hosp. Rep., 86, 191.

HOFMEISTER, quoted by Spivak (1936) in The Surgical Technic. of Abdominal Operations, $43 \mathrm{I}-436$.

KIEFER, E. D. (1942), Four. A.M.A., 120, 819.

MARSHALL, S. F. (1942), Surg. Clin. North. Am., 24, 624

MIMPRISS, T. W., and ETHERIDGE, F. G. (Öct., 1944), Brit. Med. Four., 466 .

OGILVIE, W.'H. (1938), Lancet, 2, 295.

O'HARA, J. W. (1900), Am. Four. Obst. (St. Louis), 42, 81.

PANNETT, C. A. (I945), Brit. Four. Surg., 32, 418.

PAUCHET'(1934), Pratique chir., 19, 132.

WANGENSTEEN, Prof. O.H. (Čhas. Thomas, Springfield, Illinois 1942), Intestinal Obstructions, 232.

\section{A NEW JOURNAL}

We have just received a copy of a Journal which is at once both new and old. It is the first British number of The Journal of Bone and Joint Surgery which will in future be published alternately in Boston and London.

This publication fills a long felt want in this country where there has been no Journal devoted exclusively to orthopaedic and fracture surgery. It has been produced in complete conformity with its American cousin and probably most subscribers will bind both issues together, thus obtaining a record of modern orthopaedic surgery as it is practised on both sides of the Atlantic.

It augurs well for the future of this venture that the British Editor is Sir Reginal Watson-Jones, and the Chairman of the Editorial Board, Sir Harry Platt. They are assisted by an Editorial Board made up of leading orthopaedic surgeons in this country, Australia, Canada, New Zealand and South Africa. His Majesty the King has conveyed his best wishes for the success of this new publication in a jetter which is printed as a frontispiece.

The editorials describe how the British Journal of Bone and Joint Surgery was born and introduce a symposium of articles on the treatment of recurrent dislocation of the shoulder. The latter are contributed by no less than twelve authors ranging from Toronto to Stockholm, seven being from London. Smith-Petersen of Boston contributes a characteristically forceful account of the Evolution of Mould Arthroplasty of the Hip Joint, an oper ration which he has introduced and perfected during many years. It is based on a Moynihan Lecture delivered in the University of Leeds last May, and W. E. Gallie's article on Recurring Dislocation of the Shoulder is likewise based on a Moynihan Lecture given at the Royal College of Surgeons in September.

K. I. Nissen writes on Morton's Metatarsalgia and in a lucid and well documented article dèscribes the results he has obtained by local resection of the plantar digital nerves on 35 occasions. There are numerous other valuable contributions, but quite outstanding amongst them is Sir Thomas Fairbank's review of Osteogenesis Imperfecta, which is illustrated by thirteen cases of this rare but interesting condition. Sir Thomas's knowledge of bone diseases must be well nigh unrivalled in this country, and one hopes that this article one day may form a single chapter in an atlas of skeletal affections by this author.

The new Journal also contains very full accounts of current orthopaedic meetings in Great Britain and the Dominions and in addition some interesting historical footnotes. An enormous amount of care has been expended in publishing this periodical and the excellence of the printing and reproductions is one of its notable features. We are delighted to welcome our new contemporary, and we wish it the success which it well deserves. 